\title{
A EJA E A FORMAÇÃO DE UMA CONSCIÊNCIA CRÍTICA E CIDADÃ NA PERSPECTIVA DE PAULO FREIRE
}

\author{
Terezinha Doraci Azzolin Allessi ${ }^{1}$ \\ Marli Pereira de Barros Dias²
}

\section{RESUMO}

O presente artigo visa analisar como o pensamento e o método de Paulo Freire são relevantes no processo de uma educação emancipadora com vistas à humanização dos sujeitos e à conquista de direitos e de cidadania. A pergunta de partida é a seguinte: como as aulas da EJA podem contribuir para desenvolver o senso crítico dos estudantes e a consciência individual e coletiva, na conquista de direitos e da cidadania? O objetivo geral é analisar o pensamento e o método de Paulo Freire na alfabetização de Jovens e Adultos, visando ao desenvolvimento da consciência crítica e à construção da cidadania, a partir do resgate de direitos fundamentais, individuais e coletivos. Os objetivos específicos são: verificar o perfil do estudante da EJA; promover a consciência individual e coletiva, a conquista de direitos e cidadania, a partir do pensamento de Paulo Freire; analisar a concepção freiriana de cidadania. A metodologia utilizada foi a pesquisa bibliográfica das obras de Paulo Freire e de alguns outros autores cuja abordagem no âmbito da educação de direitos e de cidadania se interligam ao pensamento de Freire. Ao término desta pesquisa, podemos concluir que a EJA deve ser para o estudante jovem e adulto o despertar para o mundo, para que se sinta inserido na sociedade e consciente de seus direitos e de suas responsabilidades. Isso é possível por meio da proposta da educação libertadora e do diálogo, como ferramenta fundamental, a partir do pensamento de Paulo Freire.

Palavras-chave: Cidadania. Educação de Jovens e Adultos. Educação libertadora. Paulo Freire.

'Graduada em Pedagogia, pela faculdade UNINA. E-mail:terezinhaallessi@gmail.com

${ }^{2}$ Professora da Faculdade UNINA. Doutora em Teoria Jurídico-Política e Relações Internacionais, pela Universidade de Évora, Portugal. E-mail: Marli.dias@unina.edu.br 


\section{ABSTRACT}

This article aims to analyze how Paulo Freire's thought and method are relevant in the process of an emancipatory education with a view to the humanization of subjects and the conquest of rights and citizenship. The starting question is the following: how can EJA classes contribute to develop students' critical sense and individual and collective awareness, in the conquest of rights and citizenship? The general objective seeks to analyze the thinking and method of Paulo Freire in the literacy of Young People and Adults aiming at the development of critical awareness and the construction of citizenship, from the rescue of fundamental, individual and collective rights. The specific objectives are: to check the profile of the EJA student; promote individual and collective awareness, the conquest of rights and citizenship, based on Paulo Freire's thinking; analyze Freir's conception of citizenship. The methodology used was bibliographic research and qualitative analysis of the works of Paulo Freire and the thoughts of some authors, whose approach in the field of education, rights and citizenship, are intertwined with Freire's thought. At the end of this research we can conclude that, EJA should be for the young and adult student, the awakening to the world, so that he / she feels inserted in society and aware of their rights and their responsibilities. This is possible through the proposal of liberating education and dialogue, as a fundamental tool, based on Paulo Freire's thinking.

Keywords: Citizenship; Youth and Adult Education; Liberating education; Paulo Freire.

\section{INTRODUÇÃO}

A Educação de Jovens e Adultos (EJA) é hoje, no Brasil, uma questão também de inclusão social. Nesse sentido, esta pesquisa visa analisar a pedagogia de Paulo Freire, na qual o diálogo entre professor e aluno é fundamental, assim como a valorização do conhecimento prévio de cada estudante. Essa concepção de ensino-aprendizagem permite superar o método tradicional, oportunizando a edificação do grupo de estudantes jovens, adultos e idosos, mediante os referenciais de vida de cada um e estabelecendo um aprendizado mais efetivo, a partir de sua realidade.

Como egressa da EJA, minha experiência não foi muito animadora, e somente continuei os estudos por ser um desejo pessoal cursar uma faculda- 
de. Minhas lembranças da EJA são de aulas muito cansativas, que seguiam o modelo tradicional e em que somente o professor falava. Ele costumava usar o quadro como o recurso mais importante. Os alunos, por sua vez, copiavam tudo o que era escrito no quadro e eram tratados como se nada soubessem. Sendo assim, nossos conhecimentos prévios eram ignorados, ao contrário do que prega a pedagogia de Paulo Freire. Essas memórias e constatações foram a motivação para realizar esta pesquisa, buscando conhecer melhor o pensamento e o método de ensino de Paulo Freire, enquanto possibilidade de aprendizagem efetiva e integral de todos os estudantes dessa modalidade de ensino.

A alfabetização de jovens e adultos é um tema de grande relevância para a atual educação nacional. Entre as várias modalidades de ensino, destaca-se a EJA, que tem como foco principal a instrução de jovens e adultos que, por alguma circunstância, geralmente de cunho social e/ou financeiro, não tiveram a oportunidade de concluir o ensino básico dentro da faixa etária considerada convencional.

A EJA, no âmbito nacional, é formada pelo Ensino Fundamental e pelo Médio, oferecendo também a oportunidade de integrar-se aos cursos de Educação Profissional. Dessa maneira, o estudante poderá qualificar-se não só nos níveis fundamental e médio, como também ter a qualificação de um ensino profissionalizante, possibilitando-Ihe integrar-se ou retornar ao mercado de trabalho.

A capacidade de inclusão que a EJA possui e o seu valor enquanto educação voltada também para a autonomia e cidadania, remete-nos ao educador brasileiro Paulo Freire, conhecido como o precursor da EJA, a partir da concepção de uma pedagogia crítica e libertadora, na qual o educando é o centro do processo educativo. Freire é considerado um dos principais pensadores da história da pedagogia no Brasil, na América Latina e com alcance mundial, sendo o influenciador do movimento chamado Pedagogia Crítica.

Dentre os vários fundamentos descritos por Paulo Freire, temos o entendimento de que o professor, mergulhado na ideia da Pedagogia da Esperança, encoraje o aluno a transformar a si próprio e, consequentemente, o ambien- 
te em que vive. Nesse sentido, o professor vai além da alfabetização, que não está focada simplesmente no ensinar a ler e a escrever, mas comprometido com a construção do conhecimento, juntamente com os estudantes, visando que eles desenvolvam o aprendizado de modo significativo e para além dos livros.

Ante o exposto, o propósito deste artigo é responder à seguinte pergunta de partida: como as aulas da EJA podem contribuir para desenvolver o senso crítico dos estudantes e a consciência individual e coletiva, na conquista de direitos e da cidadania?

Para atender aos objetivos propostos, o estudo foi realizado por meio de pesquisa bibliográfica, que, segundo Cervo, "busca conhecer e analisar as contribuições culturais ou científicas do passado existente sobre um determinado, tema ou problema". (CERVO, 1983, p. 55).

Assim sendo, por meio de análise qualitativa, esta pesquisa compreende a revisão bibliográfica (livros, artigos, dissertações, teses, legislação, internet) e segue as seguintes etapas: levantamento de dados sobre a temática estudada, seleção e armazenamento dos dados e, posteriormente, sua análise.

Partimos da hipótese de que, se a EJA for influenciada efetivamente pelo pensamento e metodologia de Paulo Freire, poderá fazer a ligação do estudante com o mundo em que vive e essa deve ser valorizada em sala de aula e assim proporcionar ao educando a sua pertença no mundo, incentivando-o a alterar a sua realidade e sendo um agente ativo e transformador dessa mesma realidade.

\section{REFERENCIAL TEÓRICO}

Nossa pesquisa busca evidenciar o pensamento e o método de Paulo Freire, que é um dos maiores pensadores do nosso país e é conhecido e reconhecido em vários países ao redor do mundo, sendo o influenciador do movimento denominado Pedagogia Crítica e defensor da pedagogia libertadora, que visa a uma educação crítica em prol da transformação social.

Esta pesquisa bibliográfica também teve como foco o pensamento de al- 
guns autores cuja abordagem no âmbito da educação, de direitos e de cidadania se alinham ao pensamento de Freire. Entre eles: Alves, Amaral, Arcanjo, Hannah Arendet, Pierre Boudieu. Também foram usados documentos como a Constituição Federal do Brasil de 1988 e outros. Com este estudo foi possível perceber que, no geral, todos consideram a Educação como o alicerce para o pleno desenvolvimento da cidadania e de uma nação.

No que se refere às leis, cabe destacar a contraposição entre a primeira Constituição Brasileira Republicana e a Constituição Cidadã de 1988. A primeira Constituição Federal, de 1821, a primeira depois da Proclamação da República, no seu artigo 179, diz que a "instrução primária era gratuita para todos os cidadãos" (ARCANJO, p. 166). No entanto, sabe-se que, no decorrer da História do Brasil, essa educação era destinada somente à elite, que formava a minoria da população brasileira.

A Constituição de 1937 tira do Estado a carga para a formação educacional do país.

A constituição de 1937 fez o Estado abrir mão da responsabilidade para desempenhar um papel subsidiário, e não central, em relação ao ensino. O ordenamento democrático alcançado em 1934, quando a letra da lei determinou a educação como direito de todos e obrigação dos poderes públicos, foi substituído por um texto que desobrigou o Estado de manter e expandir o ensino público (GHIRALDELLI JR., 2008, p. 78).

Na verdade, a Constituição de 1937 foi escrita com a intenção de beneficiar o Estado, deixando-o livre da responsabilidade com a educação e, desse modo, patrocinando o Ensino Profissionalizante, em busca de mão de obra para atender a demanda industrial da época. Seu objetivo era formar operadores de máquinas, mas sem qualquer senso crítico, pois não havia a intenção de transmitir o conhecimento científico.

Na década de 1960, surgiu Paulo Freire com uma proposta cujo objetivo era o de formar pessoas críticas. Freire tinha o anseio de que a educação fosse o caminho para que o Brasil se tornasse um país mais igualitário e mais justo. Mas, com o regime militar, esta proposta foi colocada de lado e Paulo Freire foi "convidado" a se retirar do país. 
Paulo Freire via na educação um caminho para que o ser humano tivesse uma formação plena. Formação que, para ele, era a preparação para a vida, com o desenvolvimento de valores ligados a uma proposta política e com uma pedagogia libertadora, vital para a edificação de uma sociedade justa e igualitária. Segundo o educador,

Não é possível atuar em favor da igualdade, do respeito aos direitos à voz, à participação, à reinvenção do mundo, num regime que negue a liberdade de trabalhar, de comer, de falar, de ler, de discordar, de ir e vir, a liberdade de ser. (FREIRE, 2002, p. 193)

A partir de 1964, durante o regime militar, a proposta pedagógica de Paulo Freire foi interrompida e passou a vigorar a pedagogia dos dominantes. Nessa fase sombria da história brasileira, foi criado o Movimento Brasileiro de Alfabetização (MOBRAL), com o objetivo de acabar com o analfabetismo no Brasil. Desse modo, a proposta de Paulo Freire deixou de ser valorizada, por não agradar aos governantes da éoca, e ele foi exilado do Brasil.

A educação voltada ao público jovem e adulto criada pelo MOBRAL tinha uma proposta pedagógica funcional e apenas visava ensinar a ler e a escrever, usava cartazes, fichas, família silábica, assim formando leitores funcionais. $\bigcirc$ MOBRAL não utilizava o diálogo, o qual é um diferencial do método Paulo Freire. Para Freire, sem o diálogo, a formação crítica do estudante fica comprometida. E a pretensão do MOBRAL era, de fato, apenas formar pessoas capazes de produzir e consumir.

A Educação de Jovens e Adultos no Brasil chegou aos anos de 1990 carente de uma revisão pedagógica. Os estudantes jovens e adultos que buscavam esses programas, em sua grande maioria, eram pessoas que não foram muito bem-sucedidas na escola e que foram excluídas do sistema escolar por diversas situações. Essa condição enfatiza o desafio pedagógico da EJA, ou seja, assegurar que essas pessoas que foram excluídas da escola regular, independentemente do motivo, tenham acesso à cultura letrada que permita um maior conhecimento do mundo do trabalho, da cultura e da política.

E, por ser de suma importância, vale ressaltar o que a Constituição Federal 
de 1988 nos fala sobre a formação do cidadão:

Art. 208. O dever do Estado com a educação será efetivado mediante a garantia de:

I - ensino fundamental obrigatório e gratuito, assegurada, inclusive, sua oferta gratuita para todos os que a ele não tiverem acesso na idade própria;

II - progressiva universalização do ensino médio gratuito (BRASIL, 1988).

Com o passar dos anos, começou a haver uma preocupação com critérios que nos remetem à concepção de Educação deixada por Paulo Freire. Porém, para que essa transformação possa acontecer, o educador deve assumir a concepção da EJA como sendo um local de transformação e de humanização.

A Lei de Diretrizes e Bases da Educação Nacional (LDB) n 9.394/96 diz que o Ensino Fundamental é um direito do cidadão, e o Estado tem a responsabilidade de atender a todos, com garantia de acesso e permanência. Essa lei contempla as necessiddes e interesses dos estudantes, valorizando suas experiências de vida e deve ser distinta da educação na escola regular.

Atualmente, os cursos na modalidade EJA se apresentam da seguinte maneira: presencial, semipresencial e a distância, além de exames supletivos. Com base nas Diretrizes, a metodologia da EJA faz referência aos conteúdos dos respectivos níveis (Ensino Fundamental e Ensino Médio). Quanto à disposição curricular, elas incluem uma base nacional comum que deve ser seguida pelos sistemas de ensino e que considere as características locais de cada região referentes à sociedade, à cultura, à economia da população dessas localidades, valorizando a realidade de cada estudante.

Um dos objetivos da EJA, aquele que é mais subjetivo, é ressignificar vidas. As diretrizes da Educação voltadas à EJA apontam nesse sentido, mas, infelizmente, na prática, nem sempre é o que acontece. O que muito se vê ainda é a concepção bancária, que foi insistentemente criticada por Paulo Freire, na qual inexiste o diálogo e a problematização e o professor é o detentor do saber: é ele quem fala e ensina. Quanto ao estudante, é considerado o sujeito que 
não sabe nada e apenas deve ouvir. Mas, não podemos responsabilizar apenas os professores ou a escola pública. Este é um problema em que o sistema de ensino infelizmente está imerso e acaba por reproduzir hierarquicamente os interesses e a cultura de classe e raça.

A reprodução da cultura da elite nas escolas, como sendo universal, nega a cultura das classes menos favorecidas e, de acordo com Pierre Bourdieu, isto é uma violência simbólica. Ou seja, a ação pedagógica da escola dá continuidade ao que é determinado pela elite dominante, que prega a meritocracia, a qual que se refere à ideologia do dom. De acordo com essa ideologia, alguns têm dom para aprender e outros não, e isso é passado como se fosse algo natural. Nesse contexto, "a ação pedagógica reproduz a cultura dominante, reproduzindo também as relações de poder de um determinado grupo social" (BOURDIEU; PASSERON apud ROSENDO, 2009, p. 5).

A cultura escolar age como se todos fossem iguais, cria exercícios repetidos com o intuito de criar um hábito, para que certa cultura se reproduza. E os professores ensinam da maneira como foram ensinados, sem perceber que essa violência simbólica também Ihes foi imposta pela classe dominante.

A libertação da condição de dominado relaciona-se com a formação do(a) cidadão(ã) consciente e crítico(a). Conforme explica Freire, o conhecimento por meio da educação é uma ferramenta que capacita o ser humano a agir no mundo e essa ação gera mudança. Para que o jovem e o adulto possam sentir-se partícipes da história. Segundo Freire,

[...] o que temos a fazer, na verdade, é propor ao povo, através de certas contradições básicas, na sua situação existencial básica, concreta, presente, como problema que, por sua vez, o desafia e, assim, Ihe exige resposta, não só no nível intelectual, mas no nível da ação. (FREIRE, 2014, p. 120).

Verificamos a importância da pedagogia de Paulo Freire, na qual ele afirma que a educação tem um papel importantíssimo na conscientização dos estudantes para o entendimento da concepção de cidadania. Entendendo que, cidadão ativo é aquele que não se deixa manipular pelas classes dominantes, 
compreende-se que a humanidade é diversificada e as pessoas física e psicologicamente não são iguais, pois pensam e agem de forma diferente umas das outras, e aquilo que as unifica é pertencerem à mesma família humana. Portanto, cidadania é o direito de exercer essa pluralidade humana. Para Hannah Arendt,

Esta nova situação, na qual a humanidade assumiu de fato um papel antes atribuído à natureza ou à história, significaria nesse contexto que o direito a ter direito, ou o direito de cada indivíduo de pertencer à humanidade, deveria ser garantido pela própria humanidade. (ARENDT, 1989, p. 332)

Este é o papel da educação no ensino regular e principalmente com os estudantes da EJA, que muitas vezes se encontram à margem da sociedade. E neste aspecto Paulo Freire aponta a educação dialógica, que colabora para a formação da cidadania, por meio da conscientização do indivíduo sobre o seu estar no mundo e sua condição social.

Apesar do aumento da procura dos jovens e adultos pela EJA, é importante ressaltar que os conteúdos educacionais, curriculares e os cursos nessa modalidade de ensino devem ser voltados para superar as desigualdades históricas e sociais, associadas à discriminação sexista, étnica e racial, à concentração de renda e à distribuição desigual de riqueza.

Podemos afirmar, de acordo com o pensamento de Paulo Freire, que a educação dialógica cria cidadãos críticos nas questões sociais do cotidiano, conscientes da sua cultura e que se apropriam dela através do diálogo com o mundo e seus pares.

Portanto, para Freire, a cidadania tem atributos de democracia, situando o homem, a mulher e os jovens na própria realidade e manifestando-se como uma construção comunitária, onde homens, mulheres e jovens passam a ter consciência da sua história, tornando-se agentes transformadores da realidade na qual estão inseridos: "não é possível atuar em favor da igualdade, do respeito ao direito à voz, à participação, à reinvenção do mundo, num regime que negue a liberdade de trabalhar, de comer, de falar, de criticar, de ler, de discordar, de ir e vir, a liberdade de ser". (FREIRE, 2002, p. 193). 
O pensamento de Paulo Freire é de profundo valor, porque ele dá voz às classes populares, que poderão encontrar a liberdade por meio da educação e da consciência crítica, pois o analfabetismo tira a voz de participação efetiva na sociedade e, geralmente, coloca o ser humano na invisibilidade.

Mas, para que tal conquista se solidifique, a EJA deve possibilitar a continuidade dos estudos a todos aqueles que não tiveram essa oportunidade em idade própria, proporcionando-Ihes um aprendizado por meio de uma metodologia diferenciada. Essa metodologia deve levar em consideração a realidade cultural, o nível de seus conhecimentos, a história de cada um, a condição socioeconômica e a diversidade étnico-racial e cultural, territorial, de gênero, entre outras.

A EJA deve estar voltada à formação integral dos estudantes e com vistas à preparação para a vida social, política e também para o mundo do trabalho, promovendo a inter-relação entre a teoria e a prática. Deve sustentar-se numa concepção crítica de educação, que deve incluir professor e estudante num processo dialógico e participativo e de reflexão, para que os discentes consigam compreender a realidade em que estão inseridos e encontrem os meios para poder transformá-la.

A pedagogia de Paulo Freire tem uma visão libertadora para a educação, na qual a intenção é a de possibilitar a humanização e a libertação dos estudantes jovens e adultos, com oportunidades de criar um caminho para a emancipação do sujeito e consequentemente a transformação da sociedade.

A EJA, se estiver bem alicerçada na pedagogia de Paulo Freire, poderá colaborar na formação da consciência crítica e na transformação da sociedade, indo além da pedagogia tradicional e transformando o ato de educar em uma ação de liberdade em que, professor e estudante possam ser os atores principais. Nessa concepção de educação, o diálogo constrói o conhecimento com criticidade, favorecendo as relações dos seres humanos entre si e com o mundo e a conquista da cidadania. 


\section{CONSIDERAÇÕES FINAIS}

Neste trabalho, buscamos explicitar um pouco do pensamento e da pedagogia de Paulo Freire, na qual ele afirma que a educação deve estar sempre se movimentando e dialogando com todos os temas da atualidade e que deve introduzir elementos que contribuam para a formação crítica e cidadã dos estudantes, comprometendo-se com sua humanização. Assim, podemos compreender que a educação busca a formação crítica, cidadã e inclusiva e visa à formação de pessoas autônomas e com capacidade de discernir o que é justo para si e para o coletivo, a partir da consciência reflexiva, crítica, não alienada e capaz de lutar pelos seus direitos e cumprir com as suas obrigações. Em termos educacionais, essa concepção freiriana permite romper com o método tradicional de educação, no qual a hierarquização está presente e o estudante é tratado como alguém que nada sabe.

A concepção tradicional de escola e de ensino ainda está presente, mui-tas vezes, na realidade atual da EJA. Hoje, ainda há dificuldade em pôr em prática uma educação libertadora nessa modalidade de ensino. Trata-se de uma modali-dade um pouco complexa, que trabalha com estudantes de diversas faixas etá-rias, cujas pessoas são, na sua grande maioria, socialmente excluídas e geral-mente passam despercebidas na sociedade. Entretanto, enquanto seres huma-nos, têm uma história de vida e conhecimentos prévios, que devem ser valoriza-dos, principalmente na escola. Porém, essa valorização e compreensão da histó-ria e realidade desses alunos nem sempre é verificada, com isso surgem dificul-dades em relacionar teoria e prática.

Para que se consiga relacionar a teoria e a prática, o professor deve ter a qualificação adequada e ser capaz de estar inserido e compreender a realidade do estudante. Mas, para muitos professores, isso é uma tarefa árdua, pois, geral-mente, as condições de trabalho são precárias, com longas jornadas diárias por ter que trabalhar em mais de uma escola, não receber incentivo para a qualifica-ção profissional e ainda há por parte de muitas pessoas na nossa sociedade e também no meio educacional, o preconceito, ou seja, a concepção de que para a EJA "qualquer coisa serve". Muitas vezes, tudo isso é negligen- 
ciado pelo sistema educacional brasileiro, que, por diversos motivos, privilegia a educação hierarqui-zada e não dialógica e, portanto, segue na contramão do pensamento freiriano.

A pedagogia de Paulo Freire vê a educação como dialógica e valoriza a troca de conhecimentos entre professor e aluno, que dá munição ao estudante para desenvolver um pensamento reflexivo e crítico para poder tomar consciência da sua própria condição enquanto ser humano e da sociedade e aproximar-se e compreender a realidade na qual está inserido.

Para Freire, a educação tem um papel fundamental no processo de trans-formação social. Nesse contexto, o diálogo permite a superação da prática educa-tiva tradicional, contribuindo para que a educação possa ser libertadora. Desse modo, o professor e os estudantes são os atores principais nesse processo, no qual a liberdade e o diálogo fazem parte da produção do conhecimento e das re-lações entre as pessoas e o mundo. Essa ação acontece quando se tem a com-preensão, segundo Paulo Freire, de que "educar é um ato político" (FREIRE, 1991, p. 21).

Na concepção de Freire, a educação permite a emancipação humana, a qual favorece a superação das inúmeras formas de opressão e de dominação so-fridas pelas classes menos abastadas e marcadas pela exclusão socioeconômica e educacional.

A concepção pedagógica freiriana favorece a conscientização dos estu-dantes que estão atrelados ao sistema social vigente, que muitas vezes aliena e oprime. A pedagogia de Paulo Freire, se bem compreendida e aplicada, contribui para que os estudantes consigam se emancipar e tornarem-se agentes ativos da transformação social tão necessária em nosso país.

Algo que ficou muito claro nesta pesquisa e que não se encerra com este artigo são a fé e a confiança que Paulo Freire tinha no ser humano, no seu poder de ação para transformar a própria vida e a realidade à sua volta e, desse modo, reduzir as desigualdades e as injustiças sociais.

Neste trabalho que se finda, faço minhas as palavras de Freire: "Se nada ficar destas páginas, algo, pelo menos, esperamos que permaneça: nossa confi-ança no povo. Nossa fé nos homens e na criação de um mundo em que seja me-nos difícil amar". (FREIRE, 2014, p. 253) 


\section{REFERÊNCIAS}

A EDUCAÇÂO É UM ATO POLÍTICO. Cadernos de Ciência, Brasília, n. 24, p.21-22, jul./ago./ set. 1991. Disponível em: http://acervo.paulofreire.org:8080/xmlui/handle/7891/1357. Acesso em 12 abr.2021

AGÊNCIA SENADO. Ruth colocava "pessoas competentes" para desenvolver programas que criava, lembra FHC. Senado Notícias. Brasília, 2005. Disponível em:https://www12.senado.leg.br/noticias/materias/2009/03/05/ruth-colocava-pessoas-competentes-para-desenvolver-programas-que-criava-lembra-fhc.Acesso em 20 ago.2020.

ALVES, J. A. Lindgren. Cidadania, direitos humanos e globalização. Revista da Associação dos Magistrados Brasileiros, São Paulo, nº 7, p. 92-109, jul./dez. 1999.

AMARAL. J.J.F. Como Fazer uma Pesquisa Bibliográfica. Universidade de Medicina Federal do Ceará: NEAPI, 2007.

ARCANJO. Fernanda; HANASHIRO Midori. A História da Educação no Brasil. São Paulo, Biblioteca 24 horas, 2010.

ARENDT, Hannah. Origens do Totalitarismo - Antissemitismo, Imperialismo, Totalitarismo. São Paulo: Companhia das Letras, 1989.

BOURDIEU, Pierre; PASSERON, Jean-Claude. A Reprodução- Elementos para uma Teoria do Sistema de Ensino. Ed. Vega, Lisboa, 2009.

BRASIL. Constituição (1988). Constituição da República Federativa do Brasil. 52ª Ed. Brasília, DF: Senado federal, Edições Câmara, 2017.

BRASIL/MEC. LDB - Lei n 9394/96, de 20 de dezembro de 1996. Estabelece as diretrizes e bases da Educação Nacional. Brasília, DF: 20 de dezembro de1996.

BRASIL. Presidência da República. Secretaria Especial de Políticas para as Mulheres. Plano Nacional de Políticas para as Mulheres. - Brasília: Secretaria Especial de Políticas para as Mulheres, 2004. Disponível em: http://pfdc.pgr.mpf.mp.br/atuacao-e-conteudos-de-apoio/publicacoes/saude/plano-nacional-de-politicas-para-as-mulheres. Acesso em 25 ago. 2020.

CARVAlHO, Marcelo Pagliosa. As Políticas Para Educação de Jovens e Adultos nos governos LULA. UFMA, Maranhão, p.1-15, 2003-2010. Disponível em: https://www. anpae.org.br/iberoamericano2012/Trabalhos/MarceloPagliosaCarvalho_res_int_GT1. pdf. Acesso em 24/08/2020.

SEED-PR. História da Educação no Brasil. Curitiba, s.d. Disponível em: http://www.te- 
bgregorioteixeira.seed.pr.gov.br/modules/conteudo/conteudo.php?conteudo=8 Acesso em $12 / 08 / 2020$.

CERVO, Amado Luis; BERVIAN, Pedro Alcino. Metodologia científica: para uso dos estudantes universitários. 3 ed São Paulo: McGraw-Hill do Brasil, 1983.

CURITIBA. Secretaria Municipal da Educação. Programa de educação de jovens e adultos. Curitiba, 1993.

DCEJA CURITIBA. Diretrizes Curriculares para a Educação de Jovens e Adultos. Prefeitura Municipal de Curitiba, Secretaria da Educação Curitiba, 2012.

DOLINSKI, H Silvia. Educação de Jovens e Adultos: Análise do Processo de Construção das Diretrizes Curriculares do Estado do Paraná (1990 a 2010), In: EDUCERE XII congresso Nacional de Educação, 2015, Curitiba: PUCPR, 2015. p 1-18.

FREIRE, Paulo. Cartas a Cristina, p. 193. Editora UNESP $2^{a}$ edição revista, 2002, FREIRE, Paulo. Política e Educação. São Paulo: Cortez, 1993.

FREIRE, Paulo. Pedagogia da Autonomia - Saberes necessários à Prática Educativa. 25ª Ed. São Paulo, Paz e Terra, 1996.

FREIRE, Paulo. Pedagogia Do Oprimido. $57^{a}$ ed. Rio de Janeiro, Paz e Terra, 2014.

FREIRE, Paulo. Pedagogia da indignação: cartas pedagógicas e outros escritos. São Paulo. Editora UNESP, 2000. Disponível em: <https://cpers.com.br/paulo-freire-17-livros-para-baixar-em-pdf/. Acesso em 13 de maio de 2020.

FREIRE, Paulo. Conscientização: teoria e prática da libertação. $3^{a}$ ed. São Paulo, Centauro, 1980.

GABIONETA, Robson. A Maiêutica Socrática Como 'União' de Teorias no Teeteto. Revista Brasileira de Estudos Clássicos, UFMG, Belo Horizonte. V 28, n 2, p.35-45, 2015.

GASPAR, Géssica. A (des)valorização intelectual do estudante da EJA. Revista Discente do Programa de pós-graduação em Sociologia da Universidade Federal do Paraná, Curitiba, V.5, 432-450, 2019. Disponível em: https://revistas.ufpr.br/sclplr/article/ view/68206 Acesso em 26/08/2020.

GHIRALDELLI JUNIOR, Paulo. História da educação brasileira/Paulo Ghiraldelli JR. $2^{a}$ ed. São Paulo: Cortez, 2006.

MARCÍLIO, L Maria. Declaração de Hamburgo sobre a Educação de Jovens e Adultos - 1997, Biblioteca Virtual dos Direitos Humanos, USP, São Paulo, 1997. Disponí- 
vel em: http://www.direitoshumanos.usp.br/index.php/Direito-a-Educa\%C3\%A7\%C3\%A3o/declaracao-de-hamburgo-sobre-educacao-de-adultos.htmIAcesso em 20/08/2020.

SOARES, Leôncio José Gomes. Educação de Jovens e Adultos - Diretrizes Curriculares Nacionais. Editora DP\&A, RJ, 2002. 